\title{
PREDICTION OF THE DYNAMIC RESPONSE OF THE POTENTIOMETRIC CARBON DIOXIDE ELECTRODE
}

\author{
BART VAN DER SCHOOT* and PIET BERGVELD \\ Department of Electrical Engineering, Twente University of Technology, P.O. Box 217, \\ 7500 AE Enschede (The Netherlands)
}

(Received 30th May 1984)

\section{SUMMARY}

The dynamic behaviour of the potentiometric carbon dioxide electrode is predicted by means of a digital simulation that considers both diffusion and reaction kinetics. The method allows for complete description of the electrode response without requiring the assumption that one of these processes can be neglected. The validity of the simulation was tested experimentally by using a commercial $\mathrm{pCO}_{2}$ electrode provided with various silicone rubber and teflon membranes. The measured values are in good agreement with those of the simulation.

The dynamic response of potentiometric gas-sensing electrodes is governed by diffusion processes and the reaction kinetics of the species involved. Although several papers have been published (see, e.g. [1-4]), there is no unanimity about the rate-determining step in the response of these devices. Because of the complexity of the system, only approximate equations have been given for computation of the response time, based on assumptions that differ from one author to another.

In an attempt to solve this problem, digital simulation is examined in this paper. The model takes into account all the time-dependent processes involved; the various dynamic processes that occur simultaneously can be separated and their influence on the overall response can be studied. The validity of the simulation was checked by measuring the responses of a commercially available $\mathrm{CO}_{2}$ electrode fitted with the membranes supplied originally as well as with other teflon membranes. This investigation formed part of a project to construct a miniature carbon dioxide electrode based on an ISFET. Eventual mass production of such devices requires that all techniques and materials involved are reasonably compatible with common integrated circuit technology. In order to make a proper choice of materials and to estimate the best dimensions, the digital simulation can be used to predict the dynamic behaviour of the devices. 


\section{THEORY}

The potentiometric gas-sensing electrode was introduced by Severinghaus and Bradley [5] for the measurement of carbon dioxide in blood. It consists of a $\mathrm{pH}$ glass electrode in contact with a thin electrolyte layer which is held in position with a gas-permeable membrane. Carbon dioxide diffuses through the membrane until equilibrium is established between the internal electrolyte layer and the external sample solution or gas stream. At this equilibrium state, the $\mathrm{pH}$ of the internal electrolyte is given by the Henderson-Hasselbalch buffer equation

$$
\mathrm{pH}=\mathrm{pK} K_{1}-\log \left[\mathrm{CO}_{2}\right] /\left[\mathrm{HCO}_{3}^{-}\right] \quad\left(K_{1}=4.45 \times 10^{-7}\right)
$$

This equation describes the result of a process that actually consists of two steps [6]. The first step is the hydration of $\mathrm{CO}_{2}$ and the dehydration of carbonic acid: $\mathrm{CO}_{2}+\mathrm{H}_{2} \mathrm{O} \rightleftharpoons \mathrm{H}_{2} \mathrm{CO}_{3}$. The forward reaction is slow and might affect the dynamic response of the sensor; the rate law is pseudo-first-order

$-\mathrm{d}\left[\mathrm{CO}_{2}\right] / \mathrm{d} t=k_{\mathrm{CO}_{2}}\left[\mathrm{CO}_{2}\right] \quad\left(k_{\mathrm{CO}_{2}}=0.03 \mathrm{~s}^{-1}\right)$

The reverse (dehydration) reaction is governed by

$$
-\mathrm{d}\left[\mathrm{H}_{2} \mathrm{CO}_{3}\right] / \mathrm{d} t=k_{\mathrm{H}_{2} \mathrm{CO}_{3}}\left[\mathrm{H}_{2} \mathrm{CO}_{3}\right] \quad\left(k_{\mathrm{H}_{2} \mathrm{CO}_{3}}=20 \mathrm{~s}^{-1}\right)
$$

Equilibrium is reached when both reactions proceed at the same rate, i.e., $k_{\mathrm{CO}_{2}}\left[\mathrm{CO}_{2}\right]=k_{\mathrm{H}_{2} \mathrm{CO}_{3}}\left[\mathrm{H}_{2} \mathrm{CO}_{3}\right]$ with the equilibrium constant

$$
K=\left[\mathrm{CO}_{2}\right] /\left[\mathrm{H}_{2} \mathrm{CO}_{3}\right]=k_{\mathrm{H}_{2} \mathrm{CO}_{3}} / k_{\mathrm{CO}_{2}}=6.7 \times 10^{2} \text {. }
$$

The second step is the dissociation of carbonic acid, $\mathrm{H}_{2} \mathrm{CO}_{3} \rightleftharpoons \mathrm{H}^{+}+\mathrm{HCO}_{3}^{-}$. This reaction is believed to occur instantaneously. The actual acidity constant $K_{\mathrm{a}}$ is thus much greater than the apparent constant $K_{1}$ in Eqn. 1 for carbonic acid: $K_{\mathrm{a}}=\left[\mathrm{H}^{+}\right]\left[\mathrm{HCO}_{3}^{-}\right] /\left[\mathrm{H}_{2} \mathrm{CO}_{3}\right]=2.5 \times 10^{-4}$, whereas $K_{1}=$ $\left[\mathrm{H}^{+}\right]\left[\mathrm{HCO}_{3}^{-}\right] /\left(\left[\mathrm{CO}_{2}\right]+\left[\mathrm{H}_{2} \mathrm{CO}_{3}\right]\right)=4.45 \times 10^{-7}$. From the above expressions for $K, K_{\mathrm{a}}$ and $K_{1}$, it follows that the relationship between the various constants can be written as

$K_{\mathrm{a}}=K_{1}(1+K)$.

It must be noted that these equations describe the situation only when the internal electrolyte layer is at $\mathrm{pH}<8$. Above this $\mathrm{pH}$, other reactions such as $\mathrm{CO}_{2}+\mathrm{OH}^{-} \rightleftharpoons \mathrm{HCO}_{3}^{-}$can occur. The operation of the electrode at such high $\mathrm{pH}$ values of the internal electrolyte layer is not recommended, because the response time and linearity are unfavourably affected by the formation of carbonate ions [1]. In the concentration range investigated here, these effects can be neglected.

If the sample solution is perfectly mixed, the dynamic response is governed by the seven processes shown in Fig. 1. The first is diffusion of $\mathrm{CO}_{2}$ through the membrane; the rate is determined by the diffusion coefficient $D$ and the distribution of $\mathrm{CO}_{2}$ between the membrane and the solution, with distribu- 


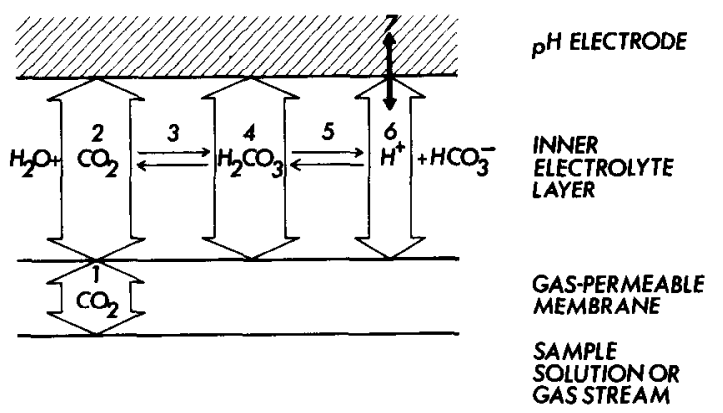

Fig. 1. The response time of the $\mathrm{CO}_{2}$ electrode is governed by: (1) diffusion through the membrane; $(2,4,6)$ diffusion in the electroly te layer; $(3,5)$ reaction kinetics; and $(7)$ the response of the $\mathrm{pH}$ electrode.

tion constant $K_{\mathrm{d}}$. This results in an apparent diffusion coefficient $D_{\mathrm{m}}=K_{\mathrm{d}} D$. The second process is diffusion of $\mathrm{CO}_{2}$ in the internal electrolyte layer with a diffusion coefficient $D_{1}$. The third involves hydration and dehydration of

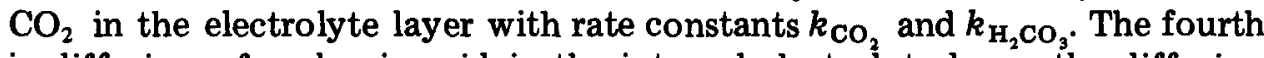
is diffusion of carbonic acid in the internal electrolyte layer, the diffusion coefficient being of the same order of magnitude as that for $\mathrm{CO}_{2}$. Steps 1,2 and 4 are determined by the dimensions of the sensor, i.e., the thickness of the membrane and of the electrolyte layer. The speed of the third step may be increased by addition of carbonic acid anhydrase [2].

Figure 1 also shows a number of processes that are not taken into account in the simulation. Thus, step 5 is the dissociation of carbonic acid, which is instantaneous and does not affect the response time. Step 6 is diffusion of hydrogen ion in the internal electrolyte layer. Because of the speed of step 5 and because $\left[\mathrm{H}_{2} \mathrm{CO}_{3}\right] \gg\left[\mathrm{H}^{+}\right]$, the $\mathrm{pH}$ at any point in the solution is governed completely by the ratio $\left[\mathrm{H}_{2} \mathrm{CO}_{3}\right] /\left[\mathrm{HCO}_{3}^{-}\right]$, and diffusion of hydrogen ion can be neglected. Finally, there is the response time of the glass electrode. At the usual dimensions of $\mathrm{CO}_{2}$ electrodes, the response of the $\mathrm{pH}$ glass electrode is fast enough not to be a limiting factor. When the dimensions of the sensor are decreased, the total response time will decrease and the response time of a glass electrode may then become important. However, with miniaturization of $\mathrm{CO}_{2}$ electrodes, probably other $\mathrm{pH}$ sensors will be used, such as metal/metal oxide electrodes [7] or ISFETs, with an inherently shorter response time. The response time of the $\mathrm{pH}$ electrode was therefore not included in the simulations.

\section{DIGITAL SIMULATION}

The digital simulation actually consists of discretization in space and time of the system under investigation, as first described by Feldberg [8]. The method has been treated more extensively by Britz [9]. 
If it is assumed that the diameter of the electrode is much greater than the thickness of the membrane and electrolyte layer, the problem can be limited to one dimension perpendicular to the electrode surface. Changes in concentrations as a function of time can then be separated into the various processes involved. In the membrane, there are no chemical reactions and only the diffusion of $\mathrm{CO}_{2}$ is of importance. There will also be a small amount of undissociated carbonic acid diffusing through the membrane but with the ratio between $\mathrm{CO}_{2}$ and carbonic acid concentrations as shown in Eqn. 4 this can be neglected. In the internal electrolyte layer, chemical reactions do occur. The concentration of $\mathrm{CO}_{2}$, for instance, may change because of diffusion but simultaneously it will decrease by formation of carbonic acid and increase by dehydration of the latter. Thus:

$\mathrm{d}\left[\mathrm{CO}_{2}\right] / \mathrm{d} t=$ diffusion - hydration + dehydration

When a number of points in the one-dimensional space is considered, at any point $i$ the concentration $c_{\mathrm{i}}$ will change over a time interval $\mathrm{d} t$ to a new concentration $c_{i}^{\prime}$. The concentration change caused by diffusion can be derived easily from the Fick's second diffusion equation, which leads [9] to

$c_{\mathrm{i}}^{\prime}=c_{\mathrm{i}}+\left(D \mathrm{~d} t / h^{2}\right)\left(c_{i-1}-2 c_{\mathrm{i}}+c_{i+1}\right)$

in which $D$ is the diffusion coefficient and $h$ is the distance between two adjacent points in the space. This equation enables concentration changes in the membrane to be calculated. To describe the situation in the electrolyte layer, the equation has to be expanded. Equations 2 and 3 give the changes in $\mathrm{CO}_{2}$ concentration caused by hydration and dehydration, so that a new concentration $c_{\imath}^{\prime}$ of $\mathrm{CO}_{2}$ in point $i$ is given, in accordance with Eqns. 6 and 7, by

$$
\begin{aligned}
c_{\mathrm{i}}^{\prime} & =c_{\mathrm{i}}+\left(\mathrm{Dd} t / h^{2}\right)\left(\left[\mathrm{CO}_{2}\right]_{i-1}-2\left[\mathrm{CO}_{2}\right]_{i}+\left[\mathrm{CO}_{2}\right]_{i+1}\right)-k_{\mathrm{CO}_{2}}\left[\mathrm{CO}_{2}\right]_{i} \mathrm{~d} t \\
& +k_{\mathrm{H}_{2} \mathrm{CO}_{3}}\left[\mathrm{H}_{2} \mathrm{CO}_{3}\right]_{i} \mathrm{~d} t
\end{aligned}
$$

So far, the procedure is quite straightforward, but the processes that take place at the various interfaces of the electrode need closer examination. First, at the surface of the $\mathrm{pH}$ electrode, diffusion takes place in only one direction. One extra point is therefore defined; this point is virtually in the $\mathrm{pH}$ electrode and follows the concentration of the surface point at all times so that no diffusion takes place between these points. Secondly, the diffusion coefficient in the polymeric membrane material $\left(D_{m}\right)$ may differ from that in the solution $\left(D_{1}\right)$. The equation used at the point defined at the interface between the electrolyte layer and the polymeric membrane has to be separated in two parts:

$\mathrm{d} c_{\mathrm{i}} / \mathrm{d} t=\left(D_{1} \mathrm{~d} t / h^{2}\right)\left(c_{i-1}-c_{i}\right)+\left(D_{\mathrm{m}} \mathrm{d} t / h^{2}\right)\left(c_{i+1}-c_{\mathrm{i}}\right)$

At the outside of the membrane, it is assumed that the sample solution is ideally mixed. The point located there can thus be the last point considered in the simulation and its concentration can be changed at will. 
The method outlined above serves to describe the new situation of the system after a time interval $d t$. From this point, the whole procedure can be repeated for any desired number of time intervals and thus the behaviour of the system with time can be investigated. The accuracy of the simulation depends, of course, on the number of time steps and the size of the space increments. The relationship between space and time intervals is given in the expression $\lambda=D \mathrm{~d} t / h^{2}$ as shown in Eqn. 7. Its value must not exceed $\lambda=0.5$ if a stable simulation result is to be obtained [9]. If both the electrolyte layer and the membrane are divided in ten space intervals, the $90 \%$ response will be reached within some thousands of time steps. This task can be completed within an acceptable computation time.

\section{RESULTS}

\section{Results of simulation}

The parameters that are varied in the simulation are the direction of the change in $\mathrm{CO}_{2}$ concentration, the dimensions of the sensor and the diffusion coefficient in the membrane material. The inner electrolyte contains $0.005 \mathrm{M}$ hydrogen carbonate in all cases. The time scale in the following figures is in seconds while the dimensions are as indicated. As is obvious from Eqn. 7, the time increments $\mathrm{d} t$ are proportional to the square of the space increments, thus if the dimensions of the sensor are increased by a factor of ten, then the time scale will expand hundredfold, if only diffusion is considered.

Figure 2 shows the $\mathrm{pH}$ change at the surface of the glass electrode as a result of a stepwise increase or decrease of the $\mathrm{CO}_{2}$ concentration in the sample solution. It can be seen that the response time depends on the direction of the change in $\mathrm{pCO}_{2}$. This phenomenon is well known for common membrane electrodes as described by Morf et al. [10] and it is independent of absolute activity levels.

There is no unanimity in the literature whether or not the hydration of $\mathrm{CO}_{2}$ plays a role in the response time of the electrode. With the present
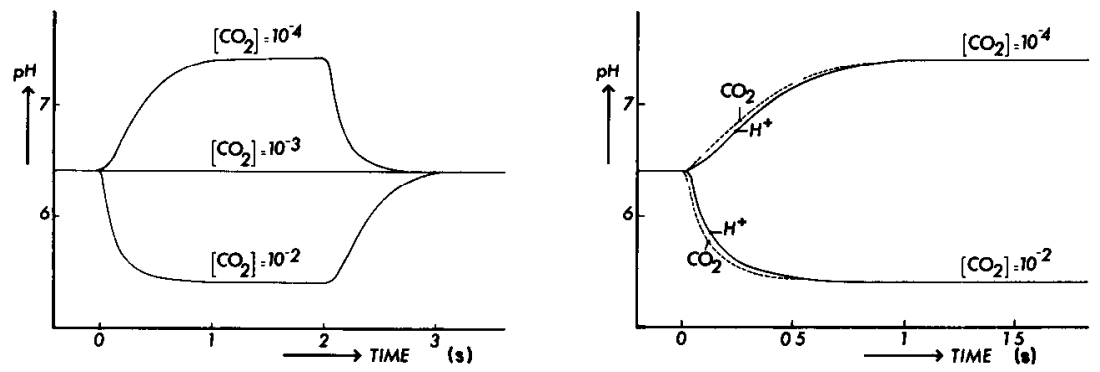

Fig. 2. The direction of the change in $\mathrm{CO}_{2}$ concentration governs the speed of response. Stepwise changes occur at $t=0$ and $t=2 \mathrm{~s}$.

Fig. 3. Difference between the change in $\mathrm{CO}_{2}$ concentration (dashed lines) and $\mathrm{pH}$ (solid lines) at the surface of the glass electrode. 
simulation, it is possible not only to predict the $\mathrm{pH}$ response but also to follow the concentration of $\mathrm{CO}_{2}$ in the sensor. In Fig. 3, the dashed line represents the $\mathrm{CO}_{2}$ change at the glass electrode surface while the solid line gives the change in $\mathrm{pH}$. It must be noted that the time scale in this figure is absolute because the hydration of $\mathrm{CO}_{2}$ is independent of the dimensions of the sensor.

It is obvious that the thinnest membrane with the highest diffusion coefficient will yield the fastest sensor. There are, however, some limitations in the choice of the membrane, such as the mechanical strength. Figure 4 shows the response of a stepwise change in $\mathrm{pCO}_{2}$ for different membranes. A diffusion coefficient $D=10^{-5} \mathrm{~cm}^{2} \mathrm{~s}^{-1}$ is typical for silicone rubber, whereas $D=10^{-7} \mathrm{~cm}^{2} \mathrm{~s}^{-1}$ is relevant to certain homogeneous teflon membranes. Decreasing the membrane thickness will cause the response time to drop, as can be seen in Fig. 5 for a membrane giving a low diffusion coefficient.

\section{Experimental verification}

To test the validity of the simulation, a Radiometer $\mathrm{E} 5036 \mathrm{pCO}_{2}$ electrode was used. The electrode was mounted in a flow-through assembly as shown in Fig. 6. The inlet is fitted with a stainless steel tube $(0.25 \mathrm{~mm}$ i.d.) providing a high fluid speed at the electrode surface. Stepwise changes in $\mathrm{pCO}_{2}$ of the sample solution were obtained with a four-way rotary valve which selected one of two streams of different concentration. A similar set-up was used previously to test the time response of ISFETs [11].

The dynamic response of the electrode was studied for stepwise changes in $\mathrm{CO}_{2}$ concentration between $10 \%$ and $100 \%$ partial pressure or approximately $2 \times 10^{-3}$ and $2 \times 10^{-2} \mathrm{~mol} \mathrm{l}^{-1}$. The concentration of hydrogen carbonate in the internal electrolyte layer was $0.005 \mathrm{~mol} \mathrm{l}^{-1}$ and the $\mathrm{pH}$ changes recorded were between 6.4 and 5.4 , approximately. At these concentrations, the change in hydrogen carbonate concentration caused by the dissociation of carbonic acid can be neglected.
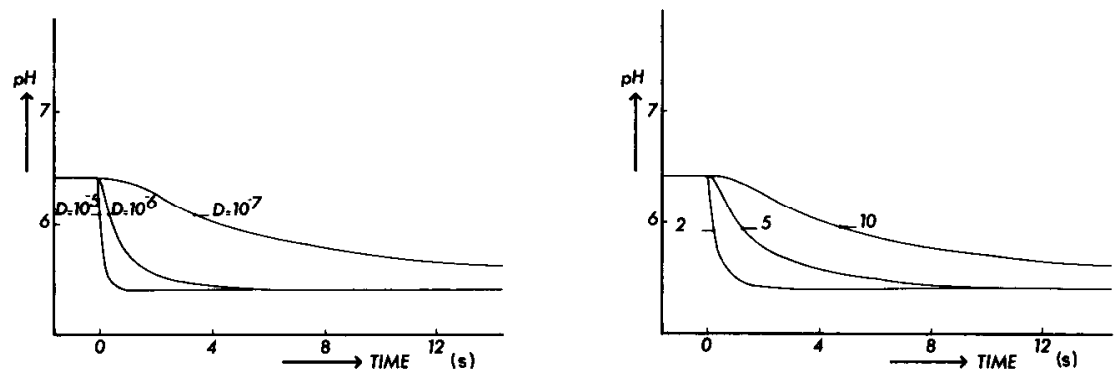

Fig. 4. Influence of the diffusion coefficient in the membrane on the response time. In all cases, the membrane is $10 \mu \mathrm{m}$ thick.

Fig. 5. The response time of the $\mathrm{CO}_{2}$ electrode as a function of the membrane thickness in the case of a teflon membrane. The numbers on the curves indicate membrane thickness in $\mu \mathrm{m}$. 


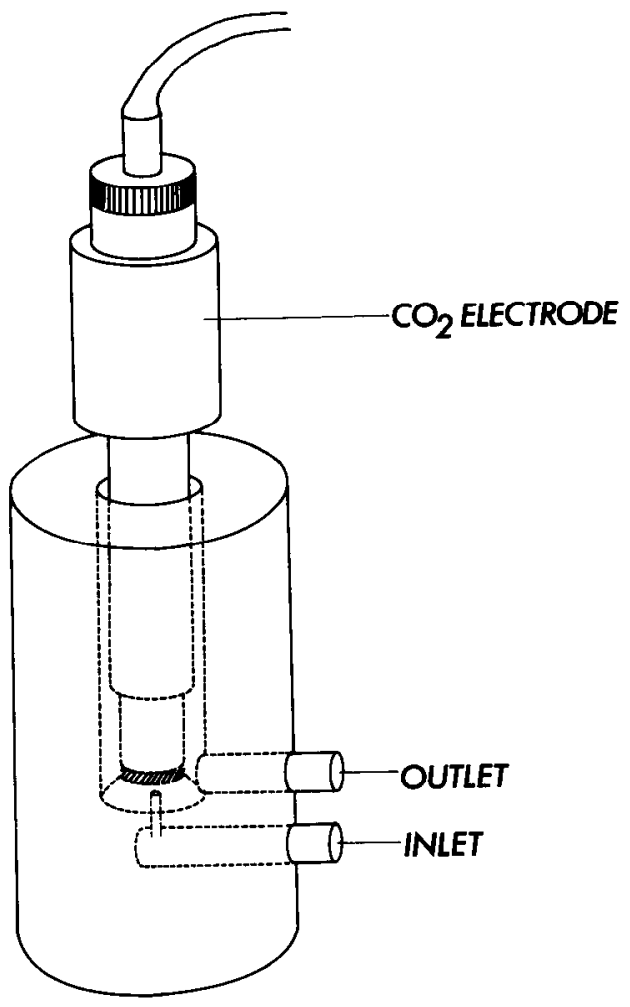

Fig. 6. Flow-through assembly used for the experimental verification of the simulation results.

The membranes tested were Radiometer silicone film $(25 \mu \mathrm{m})$, Radiometer teflon $(12 \mu \mathrm{m})$ and other PTFE membranes with a thickness of $1.5 \mu \mathrm{m}$ or $3 \mu \mathrm{m}$. Mechanically, the PTFE membranes were rather fragile and tended to stretch under the weight of the electrolyte inside the electrode. To avoid any increase in the thickness of the electrolyte layer between membrane and $\mathrm{pH}$ electrode, and so in the response time, the membrane was supported externally with a nylon net. In the construction of a miniature $\mathrm{pCO}_{2}$ electrode, this fragility is of no importance because the membrane area is only a fraction of that in a conventional electrode.

In the simulation, it was assumed that the sample solution is perfectly stirred so that there is no stagnant layer at the outside of the electrode. In practice, this situation is not achieved. Accordingly, the behaviour of the system was tested with interchange between two solutions as well as between two humidified gas streams of different concentration. The response times in the latter case were somewhat smaller and those results are summarized in Table 1, which gives the time required to reach $90 \%$ of the total response. 


\section{TABLE 1}

Results of the simulation and experimental verification of the $90 \%$ response times of the $\mathrm{CO}_{2}$ electrode for a stepwise increase or decrease in $\mathrm{CO}_{2}$ concentration in a humidified gas stream

\begin{tabular}{|c|c|c|c|c|c|}
\hline \multirow[t]{2}{*}{ Membrane } & \multirow{2}{*}{$\begin{array}{l}\text { Thickness } \\
(\mu \mathrm{m})\end{array}$} & \multirow{2}{*}{$\begin{array}{l}D \\
\left(\mathrm{~cm}^{2} \mathrm{~s}^{-1}\right)\end{array}$} & \multirow{2}{*}{$\begin{array}{l}\text { Conc. } \\
\text { change }^{\mathrm{a}}\end{array}$} & \multicolumn{2}{|c|}{$90 \%$ response time $(\mathrm{s})$} \\
\hline & & & & Simulation & Exper. \\
\hline $\begin{array}{l}\text { Radiometer } \\
\text { silicone }\end{array}$ & 25 & $10^{-5}$ & $\begin{array}{l}\text { Up } \\
\text { Down }\end{array}$ & $\begin{array}{l}3.0 \\
6.5\end{array}$ & 12 \\
\hline $\begin{array}{l}\text { Radiometer } \\
\text { teflon }\end{array}$ & 12 & $10^{-7}$ & $\begin{array}{l}\text { Up } \\
\text { Down }\end{array}$ & $\begin{array}{l}39 \\
89\end{array}$ & $\begin{array}{l}35 \\
85\end{array}$ \\
\hline PTFE & 3 & $2.5 \times 10^{-8}$ & $\begin{array}{l}\text { Up } \\
\text { Down }\end{array}$ & $\begin{array}{l}10 \\
23\end{array}$ & $\begin{array}{l}8.0 \\
22\end{array}$ \\
\hline PTFE & 1.5 & $2.5 \times 10^{-8}$ & $\begin{array}{l}\text { Up } \\
\text { Down }\end{array}$ & $\begin{array}{l}4.0 \\
8.7\end{array}$ & $\begin{array}{l}4.6 \\
12\end{array}$ \\
\hline
\end{tabular}

aConcentration change between ca. $2 \times 10^{-3}$ and $2 \times 10^{-2} \mathrm{~mol}^{-1}$ and vice-versa, indicated by up and down.

\section{DISCUSSION}

From Fig. 3 it can be seen that, with the indicated dimensions, the delay in response arising from hydration of $\mathrm{CO}_{2}$ is rather small. As conventional $\mathrm{CO}_{2}$ sensors are provided with thicker membranes and electrolyte layers, this effect will be relatively even less important. Thus it can be concluded that under these circumstances the slow hydration of $\mathrm{CO}_{2}$ plays no role in the response of the electrode and therefore the addition of carbonic acid anhydrase [2] is of no use.

The diffusion coefficient $\left(D=1.1 \times 10^{-5} \mathrm{~cm}^{2} \mathrm{~s}^{-1}\right)$ and distribution coefficient $\left(K_{\mathrm{d}}=2.6\right)$ for silicone rubber are well known [1]. Comparison of the experimental values with the simulations in Table 1 shows that they are in fair agreement.

For teflon membranes, the literature values are more scanty, varying from $2 \times 10^{-7}$ to $2 \times 10^{-8}$ with $K_{\mathrm{d}}=1.1$ [10]. Two types of teflon (the Radiometer membranes and some other PTFE membranes) were tested and the simulations were used to estimate the diffusion coefficients which are indicated in Table 1.

It is obvious that the experimental set-up used provides optimal conditions for fast response. In more practical circumstances, such as blood gas analysis equipment or in-vivo applications, the response will be influenced by the fluid dynamics of the sample solution and will thus be somewhat slower than the values indicated. For in-vitro use, however, the development of miniature sensors offers the opportunity to improve on these fluid dynamics without enlarging the sample volume.

In conclusion, it can be said that digital simulation offers a useful means of studying the behaviour of the chemical species involved in the response of 
the $\mathrm{CO}_{2}$ electrode. The mathematics are quite straightforward and simple to use. The properties of new sensors under development can be predicted very well. Teflon was used here as a membrane for technological reasons; the electrode response is almost totally governed by the thickness of this membrane, limiting the $90 \%$ response times to ca. 2 and $5 \mathrm{~s}$, respectively for an increase and a decrease in $\mathrm{CO}_{2}$ concentration. If silicone rubber could be used at thicknesses of a few micrometres, then diffusion would no longer be the limiting factor. Under those circumstances, the response would be governed by the reaction kinetics of $\mathrm{CO}_{2}$ and would be limited to a few tenths of a second.

The authors thank Mr. A. J. Verloop for the construction of the flow cell and Prof. Dr. W. E. van der Linden and Dr. M. Bos for their interest in this work.

\section{REFERENCES}

1 J. W. Ross, J. H. Riseman and J. A. Krueger, in G. Moody (Ed.), International Symposium on Selective Ion-sensitive Electrodes, Butterworths, London, 1973, p. 473.

2 T. L. Donaldson and H. J. Palmer, AIChE J., 25 (1979) 143.

3 J. Buffle and M. Spoerri, J. Electroanal. Chem., 129 (1981) 67.

4 M. A. Jensen and G. A. Rechnitz, Anal. Chem., 51 (1979) 1972.

5 J. W. Severinghaus and A. F. Bradley, J. Appl. Physiol., 13 (1955) 515.

6 D. M. Kern, J. Chem. Educ., 37 (1960) 14.

7 M. Mark dahl-Bjarme and G. Edwall, Med. Biol. Eng. Comput., 19 (1981) 447.

8 S. W. Feldberg, in A. J. Bard (Ed.), Electroanalytical Chemistry, Vol. 3, Dekker, New York, 1969, p. 199.

9 D. Britz, Digital Simulation in Electrochemistry, Springer Verlag, Berlin, 1981.

10 W. E. Morf, E. Lindner and W. Simon, Anal. Chem., 47 (1975) 1596.

11 B. H. van der Schoot, P. Bergveld, M. Bos and L. J. Bousse, Sensors Actuators, 4 (1983) 267. 